\title{
Corrigendum: Mucosal and Systemic Immune Responses to Influenza H7N9 Antigen HA1-2 Co-Delivered Intranasally With Flagellin or Polyethyleneimine in Mice and Chickens
}

\section{OPEN ACCESS}

Approved by:

Frontiers in Immunology

Editorial Office

Frontiers Media SA, Switzerland

*Correspondence:

Zhiming Pan

zmpan@yzu.edu.cn;

Xinan Jiao

jiao@yzu.edu.cn

Specialty section: This article was submitted to

Vaccines and Molecular

Therapeutics,

a section of the journal

Frontiers in Immunology

Received: 13 July 2018

Accepted: 26 July 2018

Published: 13 August 2018

Citation:

Song $L$, Xiong $D$, Song $H, W u L$, Zhang $M$, Kang $X$, Pan Z and Jiao X (2018) Corrigendum: Mucosal and Systemic Immune Responses to Influenza H7N9 Antigen HA1-2 Co-Delivered Intranasally With

Flagellin or Polyethyleneimine

in Mice and Chickens.

Front. Immunol. 9:1846.

doi: 10.3389/fimmu.2018.01846

\begin{abstract}
Li Song ${ }^{1,2,3,4}$, Dan Xiong ${ }^{1,2,3,4}$, Hongqin Song ${ }^{1,2,3,4}$, Lili Wu ${ }^{1,2,3,4}$, Meihua Zhang ${ }^{1,2,3,4}$, Xilong Kang ${ }^{1,2,3,4}$, Zhiming Pan ${ }^{1,2,3,4 *}$ and Xinan Jiao ${ }^{1,2,3,4 *}$

1 Jiangsu Co-Innovation Center for Prevention and Control of Important Animal Infectious Diseases and Zoonoses, Yangzhou University, Yangzhou, China, ${ }^{2}$ Jiangsu Key Laboratory of Zoonosis, Yangzhou University, Yangzhou, China, ${ }^{3}$ Key Laboratory of Prevention and Control of Biological Hazard Factors (Animal Origin) for Agrifood Safety and Quality, Ministry of Agriculture of China, Yangzhou University, Yangzhou, China, ${ }^{4}$ Joint International Research Laboratory of Agriculture and Agri-Product Safety of the Ministry of Education, Yangzhou University, Yangzhou, China
\end{abstract}

Keywords: avian influenza A (H7N9) virus, hemagglutinin globular head, flagellin, polyethyleneimine, mucosal subunit vaccine

\section{A corrigendum on}

Mucosal and Systemic Immune Responses to Influenza H7N9 Antigen HA1-2 Co-Delivered Intranasally With Flagellin or Polyethyleneimine in Mice and Chickens

by Song L, Xiong D, Song H, Wu L, Zhang M, Kang X, et al. Front Immunol (2017) 8:326. doi:10.3389/ fimmu.2017.00326

In the published article, there was an error in affiliations 1 and 4 as Yangzhou University was not included. The authors apologize for this error and state that this does not change the scientific conclusions of the article in any way.

The original article has been updated.

Conflict of Interest Statement: The authors declare that the research was conducted in the absence of any commercial or financial relationships that could be construed as a potential conflict of interest.

Copyright (๑) 2018 Song, Xiong, Song, Wu, Zhang, Kang, Pan and Jiao. This is an open-access article distributed under the terms of the Creative Commons Attribution License (CC BY). The use, distribution or reproduction in other forums is permitted, provided the original author(s) and the copyright owner(s) are credited and that the original publication in this journal is cited, in accordance with accepted academic practice. No use, distribution or reproduction is permitted which does not comply with these terms. 